\title{
ПРИРОДНЫЕ КОМПЛЕКСЫ
}

УДК 502.057 (571.54)

DOI 10.31554/ 978-5-7925-0575-9-11-2019-183-189

\section{НЕКОТОРЫЕ РЕЗУЛЬТАТЫ МОНИТОРИНГА ТЕМПЕРАТУРНОГО РЕЖИМА, ПОЛУЧЕННЫЕ С ПОМОЩЬЮ АВТОМАТИЧЕСКИХ МЕТЕОПРИБОРОВ (БАРГУЗИНСКИЙ ХРЕБЕТ)}

\author{
Т. Л. Ананина ${ }^{1}$, А. А. Ананин ${ }^{1,2}$ \\ ${ }^{1}$ ФБУ «Заповедное Подлеморье», Улан-Удэ, Россия, t.l.ananina@mail.ru \\ ${ }^{2}$ Институт общей и экспериментальной биологии СО РАН, Улан-Удэ, \\ Poccuя,a_ananin@mail.ru
}

Проведено детальное исследование, расчет и интерпретация температурного режима ключевого участка Баргузинского хребта на территории Баргузинского заповедника. История исследования климата на территории заповедника насчитывает более века, однако полученные данные касались побережья оз. Байкал, а метеорологические наблюдения в высотных растительных поясах были отрывочны. С 2011 г. в Баргузинском заповеднике на постоянной основе на высотном трансекте одноименного хребта проводятся наблюдения за температурными показателями (температура на поверхности почвы и приземная температура толщи воздуха). Исследования проводятся с использованием термохронов типа DS1921G и автоматических метеокомплексов «М-03». Отмечены особенности изменения сезонного терморежима Баргузинского хребта.

Ключевые слова: Баргузинский хребет, термохрон, средняя температура, напочвенная температура воздуха.

\section{Введение}

До настоящего времени термический режим территории Баргузинского заповедника был исследован недостаточно. Имеются отрывочные сведения Г. Г. Доппельмаира (1926), полученные им во время экспедиции в 1914-1915 гг., научных сотрудников заповедника Н. П. Ладохина (1948), Н. П. Ладохина и А. М. Цуркан (1948) за период 19341945 гг., В. К. Тимофеева (1948) по данным наблюдений на метеостанции «Сосновка» в 1933-1937 гг., Т. Л. Ананиной (2008) на высотном профиле в долине р. Давша в 1989-1990 гг.

С 1955 г. регулярные наблюдения за изменениями метеопараметров на побережье оз. Байкал в Баргузинском заповеднике проводятся на 
восьмисрочной метеостанции второго разряда УГМС «Баргузинский заповедник» Фиксируются: температуры толщи воздуха (средняя, минимальная, максимальная), напочвенная температура, температура почвы на глубинах 5, 10, 15, 20 см и т. д. Результаты анализа долговременных климатических наблюдений метеостанции были опубликованы (Ананин, Ананина, 2002, 2018; Ананина, Ананин, 2013, 2017). Однако данные приборов учета, расположенных в прибрежной части Баргузинского хребта, не отражают климатических особенностей всей территории.

Это обстоятельство побудило нас изучить и проанализировать терморежим высотных растительных поясов на ключевом участке Баргузинского хребта. Начиная с 2011 г., в разных точках на территории Баргузинского заповедника температура воздуха фиксируется сменными автоматическими термохронами типа DS1921G, запрограммированными на 6-срочную регистрацию температуры. В настоящее время функционируют 21 термохрон в долинах р. Давша - 19 и р. Большая 6 в окрестностях полевой базы «Давша» - 6. Их устанавливают в метеобудке или на стволе дерева, закрепляя скотчем на высоте 2 м и у поверхности земли с северной стороны, для изучения напочвенной и приземной температуры воздуха. Замена термохронов производится дважды в год, затем информация считывается на компьютер и вносится в базу данных. В 2015 г. «Заповедным Подлеморьем» были приобретены автоматические метеокомплексы «М-03» (АМ-M-03) (разработка Института мониторинга климатических и экологических систем СО РАН, г. Томск, производство ООО «Инфлай», г. Томск, автор разработки С. А. Кураков). Эти автоматические метеостанции (Бадмаев и др., 2017) предназначены для измерения величины выпадения жидких осадков (дождя), измерения температуры и влажности воздуха на поверхности почвы и высоте 2 м, атмосферного давления, глубинной температуры почвы, скорости и направления ветра, высоты снежного покрова. Регистрация информации происходит каждые 20 минут. Информация снимается 1 раз в год на флэш-карту. В 2018 г. автоматический метеокомплекс в пос. Давша был настроен на передачу измерений с накопителя в автоматическом режиме через интернет на сайт Института мониторинга климатических и экологических систем СО РАН с ограниченным режимом доступа (рис. 1А, Б).

\section{Материал и методы}

Термохроны были установлены в 2011 г. в долине р. Давша, в 12 
биотопах, последовательно расположенных на высотном трансекте ключевого участка Баргузинского хребта: луг кустарниковый (468 м над у. м.), луг разнотравный (517 м), лиственничник голубичный (518 м), ельник осоковый (517 м), сосняк брусничный (535 м), кедрач бадановый (635 м), осинник бадановый (721 м), стланик кедровый (1004 м), пихтарник черничный (1278 м), березняк парковый (1407 м), тундра черничная (1637 м), тундра лишайниковая (166 м).
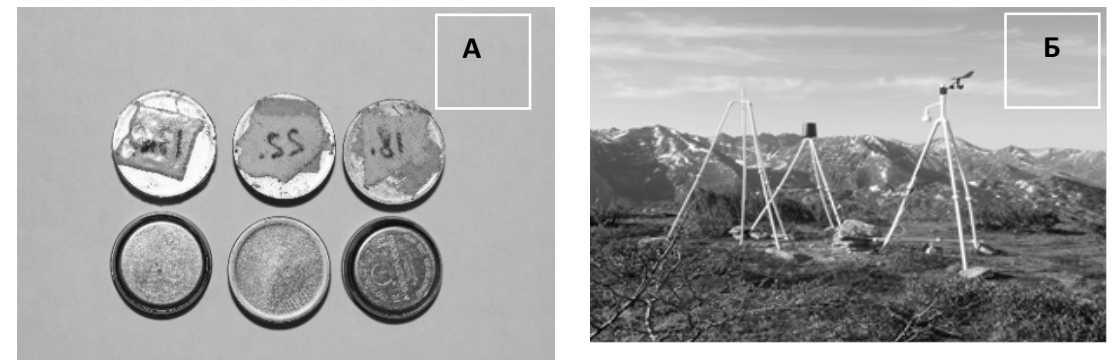

Рис. 1. Термохроны, подготовленные к считыванию информации (А), автоматическая метеостанция на горном перевале р. Давша и р. Правый Таркулик (Б)

Автоматические метеостанции установлены в 2015 г. на побережье оз. Байкал в п. Давша (468 м над у. м.) и в 30 км от побережья на горном перевале - водоразделе рек Давша и Правый Таркулик (1667 м над у. м.).

Для оценки внутригодовых изменений температурного режима на высотном трансекте и согласно климатическим особенностям северовосточного Прибайкалья выделены сезоны: лето (теплый период, длится 9 декад) - VI-1-VIII-3, зима (холодный период, 13 декад) - X3- III-3, весна (9 декад) - IV-1- V-3 и осень (5 декад) - IX-1- X-2 (переходные периоды года). Обозначены высотные выделы: побережье 458-517 м над у. м., нижняя часть горнолесного пояса - 518-721 м; верхняя часть горнолесного пояса - 722-1004 м; подгольиовый пояс растительности - 1005-1667 м.

Анализ полученных данных (средние и напочвенные температуры воздуха) за период 2011-2016 гг. выполнен в программе Excel.

\section{Результаты и обсуждение}

На температурный режим Баргузинского хребта большое влияние оказывает длинный зимний период года, который длится на Северном Байкале 13 декад, в отличие от летнего - всего 9 декад. 
Для характеристики высотных поясов выбраны средние температуры толщи воздуха (на высоте 2 м), минимальные напочвенные температуры, среднегодовые температуры воздуха, которые распределили по сезонам года. Результаты наблюдений температурного режима высотных поясов растительности по сезонам года отражены на рис. 2 и 3.

Температурный режим на высотном трансекте Баргузинского хребта имеет динамический характер. С повышением высоты над уровнем моря и удалении от Байкала он существенно изменяется (рис. 2, 3). Среднегодовые температуры воздуха за период 2011-2016 гг., по нашим расчетам, при повышении высоты на каждые 100 м, уменьшаются: в теплый период года - на $0,33^{\circ}$, в холодный - на $0,26^{\circ}$. Минимальные напочвенные температуры, напротив, с набором высоты увеличиваются: зимние - на $1,26^{\circ}$, летние - на $0,13^{\circ}$. Также, минимальные температуры на поверхности земли, были на $0,8^{\circ}$ выше температур толщи воздуха (среднегодовые значения $-1,7$ и $-2,5^{\circ} \mathrm{C}$ соответственно).

Значительная температурная разница на трансекте определяется не только изменением высоты местности над уровнем моря, но и экспозицией склона, характером растительности, горной температурной инверсией. Средние температуры воздуха имеют сниженные показатели и на низких, и на высоких отметках трансекта как в холодный, так и в теплый период года, по сравнению с температурами в нижней части горнолесного пояса растительности, где они значительно выше. В межсезонье (весной и осенью) средние температуры воздуха минимальны в подгольцовом поясе и максимальны в низкогорном (рис. 2А, 3А).

Напочвенные температуры зависят от толщины снежного покрова, периода снегонакопления - сроков его установления и разрушения на разных высотных уровнях (Ананин, Ананина, 2018). Снежный покров в горах устанавливается раньше, чем на побережье, с приходом постоянных отрицательных температур, а разрушается, наоборот, позднее, с наступлением положительных температур воздуха. Именно поэтому напочвенные температуры зимой выше в подгольцовом, летом же почва лучше прогревается в низкогорном поясе растительности. Максимальные средние и напочвенные температуры воздуха в переходные сезоны года характерны для нижней части горнолесного пояса растительности (рис. 2Б, ЗБ). Вероятно, это можно объяснить температурными инверсиями, когда нагретый теплый воздух скатывается вниз с верхней части трансекта, задерживаясь на нижних высотах, в зоне выполаживания, на отметках 635 м и 721 м над у. м. За исследуемый пе- 
риод наиболее низкие среднегодовые температуры толщи воздуха зафиксированы в высокогорье, а напочвенные - на побережье Байкала.

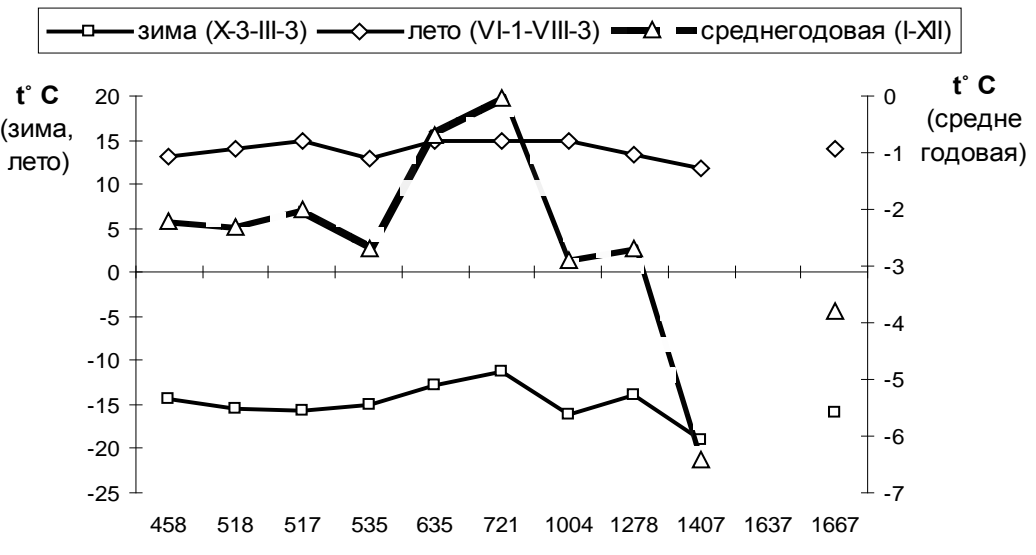

Н над ур. моря (м).

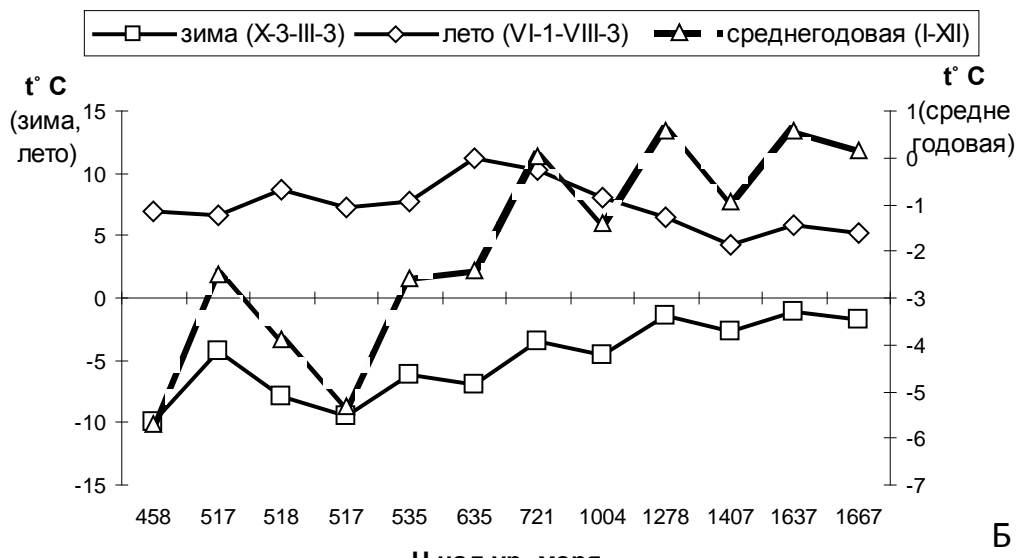

Н над ур. моря

Б

Рис. 2. Характеристика температуры воздуха в холодный (зима) и теплый (лето) периоды года, среднегодовая температура на высотном профиле Баргузинского хребта (дол. р. Давша) в 2011-2016 гг.

А - среднегодовая, зимняя и летняя температуры толщи воздуха; Б - минимальная напочвенная среднегодовая, зимняя и летняя температура воздуха

Таким образом, для температурного режима Баргузинского хребта отмечена следующая особенность - среднегодовые средние температу- 
ры воздуха с продвижением в горы по мере удаления от Байкала сначала повышаются до нижней части горнолесного пояса, а затем снижаются до гольцового пояса. Среднегодовые напочвенные температуры при движении вверх к высокогорным поясам растительности только повышаются.
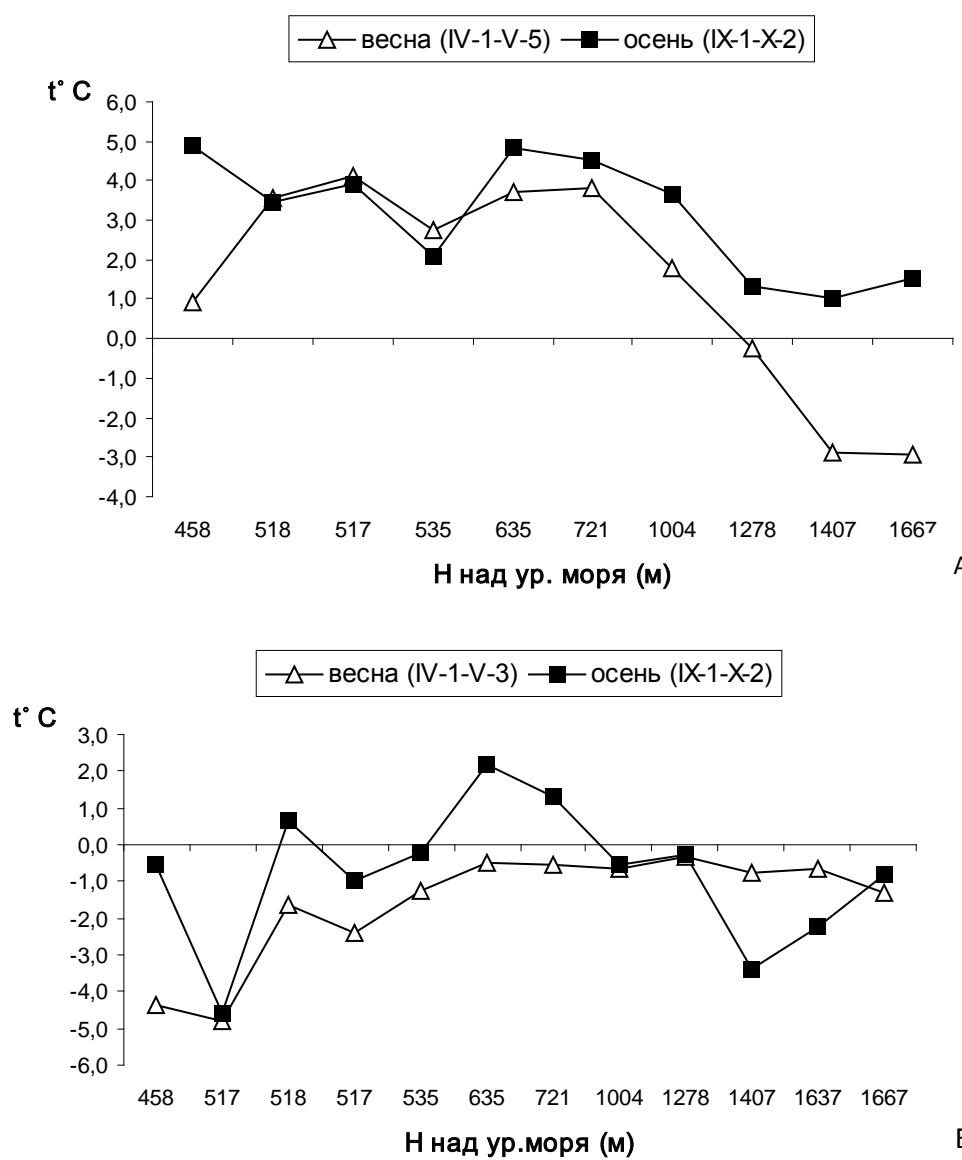

Рис. 3. Характеристика температуры воздуха в переходные периоды года (весна, осень) на высотном профиле Баргузинского хребта (дол. р. Давше) в 2011-2016 гг.

А - средняя температуры толщи воздуха; Б - минимальная напочвенная температура воздуха 


\section{Литература}

Ананин А. А., Ананина Т. Л. Многолетняя динамика климатических параметров // Мониторинг природных комплексов Северо-Восточного Прибайкалья: Тр. гос. природ. биосф. заповедника «Баргузинский». Вып. 8. Улан-Удэ: Изд-во Бурят. гос. университета, 2002. С. 9-27.

Ананин А. А., Ананина Т. Л. Характеристика снежного покрова прибрежной зоны Баргузинского заповедника (Северное Прибайкалье) в многолетнем аспекте // Снежный покров, атмосферные осадки, аэрозоли: технология, климат и экология: мат-лы II Байкальской международ. науч.-практ. конф. (25-30 июня 2018 г.). Иркутск: Изд-во ИРНИТУ, 2018. С. 34-38.

Ананина Т. Л. Использование метеоданных для оценки связи с динамикой численности доминантных видов жужелиц в экосистемах Баргузинского хребта (Северное Прибайкалье) // Биология: Теория, практика, эксперимент: мат-лы международ. науч. конф., посвящ. 100-летию со дня рождения д-ра биол. наук, проф. Е. В. Сапожниковой. Саранск, 2008. С. 85-87.

Ананина Т. Л., Ананин А. А. Изменение климата северо-восточного побережья Байкала за период 1955-2011 гг. // Природные комплексы Северного Прибайкалья: тр. Баргузинского государственного заповедника. Вып. 10. Улан-Удэ: Изд-во БНЦ СО РАН, 2013. С. 177-184.

Ананина Т. Л., Ананин А. А. Характеристика климата в регионе Северного Прибайкалья за период 1955-2015 гг. и его влияния на насекомых // Природа Байкальской Сибири: тр. заповедников и национальных парков Байкальской Сибири. Вып. 2. Улан-Удэ: Изд-во БНЦ СО РАН, 2017. С. 117-126.

Ладохин Н. П. Некоторые данные о снежном покрове Баргузинского хребта // Тр. Баргузинского гос. заповедника. Вып. 1. М., 1948. С. 177-197.

Ладохин Н. П., Цуркан А.М. Очерк местного климата приморской зоны Баргузинского государственного заповедника // Тр. Баргузинского гос. заповедника. Вып. 1. М., 1948. С. 149-173.

Тимофеев В. К. Экология Баргузинского соболя Martes zibellina priceps L. // Тр. Баргузинского гос. заповедника. Вып. 1. М., 1948. С. 3-101. 